\title{
A New Parking Guidance System For Outdoor Environment
}

\author{
R. Puviarasi, Mritha Ramalingam
}

\begin{abstract}
At the off hazard which you are any other motive force then it's miles highly difficult to choose the separation even as stopping the automobile. Reverse indicating that allows you to forestall sensor circuit tackles this problem the separation with the help of 3 LED's. we can without a great deal of a stretch mastermind this framework at the posterior of the car. This framework works with $12 \mathrm{~V}$ rechargeable battery. this newsletter discloses you how to define opposite preventing sensor. we can likewise utilize the identical concept in IR Water level Detector Circuit too. The separation in the center of vehicle and snag is comprehended through the gathering of LED's (D5 to D7).
\end{abstract}

\section{INTRODUCTION}

This project is based on identifying the space between two cars [1] to park another car that is to find out the space is sufficient for the car to be parked [2]. Thus it help the driver to park the car in the parking lot using sensor that will calculate the free space available according to space and size of the car. In some parking lot the driver won't have a clear view of the parking space in those kind of situation the parking sensor use to sense the surrounding space to park the vehicle or show that cannot be parked in the space. If the space is not enough to park the car or if the car went near to any obstacle it indicate by a buzzer sound which indicate the driver to stop the vehicle immediately. The distance that can be sensed by a sensor of minimum of $10 \mathrm{~cm}$ to maximum of 1.5 meter.

\section{REVERSE PARKING SENSOR CIRCUIT PRINCIPLE}

Stopping sensor circuit predominantly comprises of two areas, one is transmitter segment and the other is recipient segment. The transmitter area utilizes NE555 clock IC as an astable multivibrator for driving the IR transmitter. In transmitter area, 555 clock is worked in stable mode to create a sign with recurrence of $120 \mathrm{~Hz}$. The fourth stick of 555 clock is associated with supply to stay away from sudden resets.

\section{OP - AMP AS COMPARATOR \& RESULTS}

Operation amp has two inputs (non-upsetting and transforming) and one yield. The yield of operational speaker is high when non-transforming voltage is more prominent than modifying voltage. The yield voltage is low, while reversing voltage is more noteworthy than nonrearranging voltage. In the above circuit the voltages at non

Revised Manuscript Received on August 14, 2019.

R. Puviarasi, Department of ECE, Saveetha School of Engineering, Saveetha Institute of Medical and Technical Sciences, Chennai, Tamilnadu, India

Mritha Ramalingam, Faculty of Computer Systems and Software Engineering, Universiti Malaysia Pahang, Kuantan, Malaysia. rearranging pins of comparators goes about as a kind of perspective voltage and altering information voltages at comparators are contrasted with reference voltages with produce the yield. Here resistors R8 to R11 are utilized to set diverse reference voltages at their non-modifying pins.

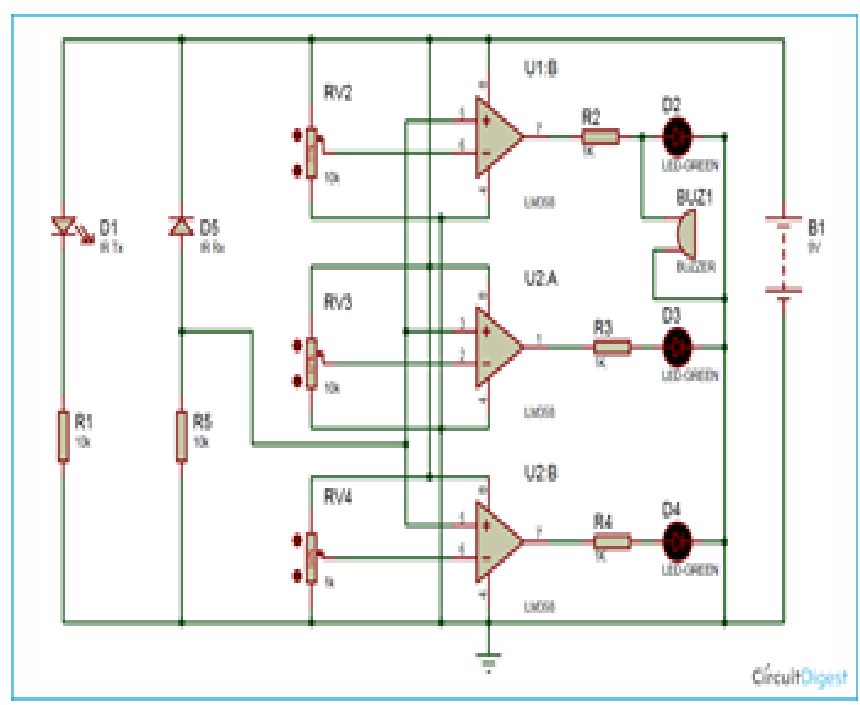

Fig.4(a). Investigation of new parking sensor circuit diagram

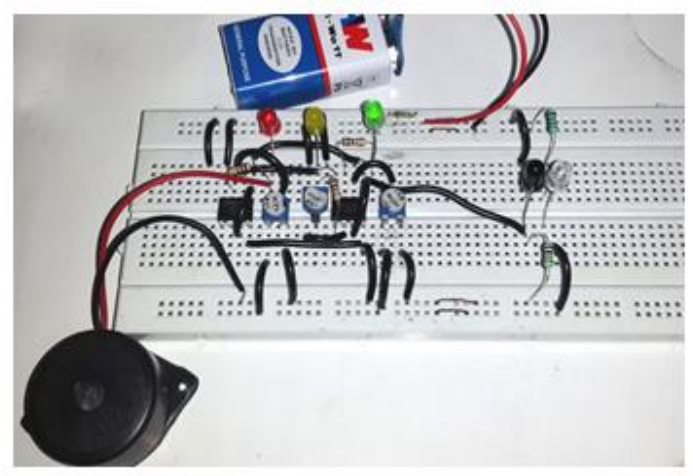

Fig .4(b). Investigation of new parking sensor circuit design

\section{Applications:}

This circuit can be utilized as a part of auto mobiles to stop the vehicle securely.

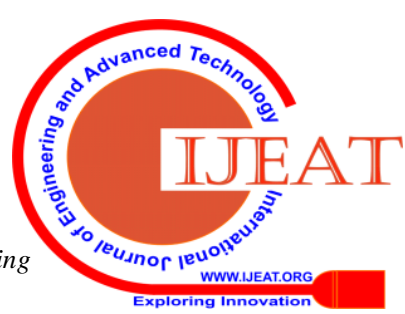




\section{A NEW PARKING GUIDANCE SYSTEM FOR OUTDOOR ENVIRONMENT}

\section{CONCLUSION}

For that reason this mission help in motive force to park in parking lot which may be very help complete for a startup driving force to park the automobile and additionally beneficial for professional driver to park in curial automobile parking space. As of for now a days in lots of building the automobile parking space are very curial to park in those type of condition this parking sensor is used. It additionally very cost efficient and more reliable.

\section{REFERENCES}

1. Parking Consultants International, Parking Guidance Systems [Online]. Sydney: Parking Consultants International, (2009).

2. Hsi-Chuan Huang, Feng-Che Tsai, Tsuo-Fei Mao "Intelligent Embedded Control Warning System For Car Reversing" Measuring Technology and Mechatronics Automation (ICMTMA), Third International Conference Shangshai, pp.849-852, Jan. 2011. 